Revista Brasil. Bot., V.31, n.4, p.559-574, out.-dez. 2008

\title{
Variações na composição florística e na estrutura fitossociológica de uma floresta ombrófila densa alto-montana na Serra da Mantiqueira, Monte Verde, MG $^{1}$
}

\author{
LEONARDO DIAS MEIRELES ${ }^{2,3}$, GEORGE JOHN SHEPHERD ${ }^{2} \mathrm{e}$ \\ LUIZA SUMIKO KINOSHITA ${ }^{2}$
}

(recebido: 02 de agosto de 2007; aceito: 17 de julho de 2008)

\begin{abstract}
Variations in floristic and phytosociological structure of an upper montane forest in Mantiqueira Range, Monte Verde, MG). The upper montane forests are known to have a different floristic composition and phytosociological structure from forests located at lower altitudes. A survey was carried out in an area of upper montane forest of the Mantiqueira Range near Monte Verde, municipality of Camanducaia, Minas Gerais State, Brazil. The main objective of this study was to analyze the effect of an altitudinal gradient on the floristic composition and vegetation structure. Seven blocks, each with five of $10 \times 10 \mathrm{~m}$ plots, were located at altitudes ranging from $1,820 \mathrm{~m}$ to $1,940 \mathrm{~m}$, and all bamboos and trees with $\mathrm{GHB} \geq 15 \mathrm{~cm}$ were sampled. A total of 1,191 individuals were included, belong to 64 tree species and two bamboos in a total of 42 genera and 26 families, including the standing dead individuals. The estimated density was 3,403 ind ha ${ }^{-1}$ and the value of the Shannon-Wiener $\left(H^{\prime}\right)$ index was 3.284 nat ind $^{-1}$. The dead biomass had the highest importance value (42.06), followed by Pimenta pseudocaryophyllus (Gomes) Landrum (24.59), Roupala rhombifolia Mart. ex Meisn. (19.98) and Drimys brasiliensis Miers (18.57). The structural parameters maximum canopy height and number of branched individuals were correlated with altitude. Although the altitudinal gradient is relatively short, a considerable degree of species substitution was observed, leading to a well-marked floristic gradient.
\end{abstract}

Key words - altitude, Atlantic Rain Forest, Mantiqueira Range, phytosociology, upper montane forest

RESUMO - (Variações na composição florística e na estrutura fitossociológica de uma floresta ombrófila densa alto-montana na Serra da Mantiqueira, Monte Verde, MG). As florestas alto-montanas são reconhecidas por apresentarem composição florística e estrutura fitossociológica distintas das florestas em cotas altitudinais inferiores. Realizou-se um levantamento fitossociológico em uma floresta alto-montana localizada na Serra da Mantiqueira, distrito de Monte Verde, Camanducaia, Minas Gerais. O principal objetivo foi analisar o efeito do gradiente altitudinal na composição florística e na estrutura fitossociológica da vegetação. Foram instalados sete blocos paralelos com cinco parcelas contíguas de $10 \times 10 \mathrm{~m}$, distantes $50 \mathrm{~m}$, entre 1.840 e $1.920 \mathrm{~m}$ de altitude. Todos os indivíduos arbóreos com CAP $\geq 15 \mathrm{~cm}$ foram amostrados, assim como as "moitas de bambu" que continham no mínimo 10 perfilhos. Foram amostrados 1.191 indivíduos, pertencentes a 64 espécies arbóreas e duas espécies de bambu, distribuídas entre 42 gêneros e 26 famílias, além da classe de indivíduos mortos. A densidade total equivalente foi de 3.403 ind ha ${ }^{-1}$ e o índice de diversidade de Shannon-Wiener $\left(H^{\prime}\right)$ foi de 3,284 nat ind ${ }^{-1}$. A biomassa morta destacou-se pelo elevado valor de importância (42,06), seguida de Pimenta pseudocaryophyllus (Gomes) Landrum (24,59), Roupala rhombifolia Mart. ex Meisn. $(19,98)$ e Drimys brasiliensis Miers $(18,57)$. Entre os parâmetros estruturais analisados a altura máxima do dossel e o número de indivíduos bifurcados estiveram correlacionados com a altitude. Uma considerável substituição de espécies foi observada, evidenciando um forte gradiente florístico, mesmo sendo o gradiente altitudinal amostrado relativamente curto.

Palavras-chave - altitude, fitossociologia, floresta alto-montana, Floresta Atlântica, Serra da Mantiqueira

\section{Introdução}

A variação da altitude é um dos principais gradientes ambientais indiretos capaz de influenciar no crescimento dos vegetais e propiciar mudanças na composição florística e na fisionomia das formações vegetacionais (Ogden \& Powell 1979, Austin et al. 1984, Proctor et al.

\footnotetext{
1. Parte da tese de mestrado do primeiro autor, Programa de PósGraduação em Biologia Vegetal/Unicamp, Campinas.

2. Universidade Estadual de Campinas, Departamento de Botânica, Caixa Postal 6109, 13083-970 Campinas, SP, Brasil.

3. Autor para correspondência: 1dmeireles@yahoo.com.br
}

1988, Pendry \& Proctor 1997). Mudanças na composição florística e na estrutura fitossociológica foram descritas por vários autores para formações florestais, em diferentes regiões dos trópicos, relacionadas ao gradiente altitudinal (Tanner 1977, Ogden \& Powell 1979, Lieberman et al. 1985, Rodrigues et al. 1989, Salis et al. 1995, Torres et al. 1997, Santos et al. 1998, Vázquez \& Givnish 1998).

Salis et al. (1995) e Torres et al. (1997) sugeriram a existência de dois conjuntos florísticos para as florestas estacionais semidecíduas no Estado de São Paulo, em resposta a um longo gradiente altitudinal. Posteriormente, Oliveira-Filho \& Fontes (2000), estudando os padrões florísticos da Floresta Atlântica no Sudeste do Brasil, 
reconheceram a altitude, seguida da precipitação e temperatura, como os principais fatores associados a maior parte da variação observada na separação de formações florestais desta região. Scudeller et al. (2001) também reconheceram a influência da altitude na ordenação de diferentes áreas da Floresta Atlântica, evidenciando ser esta uma variável indispensável para a caracterização do ambiente.

Lieberman et al. (1985), nas florestas da Costa Rica, demonstraram ocorrer uma substituição florística ao longo de um curto gradiente altitudinal, sugerindo vários outros fatores que alterariam a composição florística das florestas tropicais dentro de uma província climática. Nas formações florestais brasileiras, poucos foram os estudos que exploraram a influência da altitude numa escala local (Silva \& Leitão Filho 1982, Rodrigues et al. 1989, Santos et al. 1998), conhecendo-se muito pouco dos fatores ambientais envolvidos na organização das comunidades vegetais nas escarpas das grandes serras.

Comparações entre florestas tropicais, em diferentes altitudes, demonstraram que florestas montanas são menores na estatura, apresentam maior densidade de indivíduos, número menor de espécies e famílias, sendo floristicamente distintas das florestas das terras baixas, além de apresentarem um acentuado epifitismo vascular e/ou avascular (Lieberman et al. 1996, Hamilton et al. 1995). Para Whitmore (1998) a variação mais evidente na estrutura e na fisionomia nas florestas tropicais, associada ao aumento da altitude, está relacionada com a superfície do dossel. Este varia de irregular, em uma floresta predominantemente mesófila, para um dossel baixo e plano, composto por árvores mais delgadas, usualmente com troncos retorcidos abaixo das copas e com predomínio de microfilia, característico de uma formação alto-montana. No Brasil, Veloso (1992) denominou formações similares, com o dossel podendo alcançar até $20 \mathrm{~m}$ de altura, como floresta ombrófila densa alto-montana, incluindo também as matas nebulares.

No Sudeste brasileiro, a Serra do Mar e a Serra da Mantiqueira apresentam desníveis altitudinais capazes de alterar a fisionomia das comunidades florestais nelas presentes. Estas serras alcançam cerca de $2.000 \mathrm{~m}$ de altitude na Serra do Mar e 2.800 m na Mantiqueira Meridional (Moreira \& Camelier 1977). Hueck (1972) registrou a ocorrência de matas de altitude ou de neblina no topo dessas serras, com limite inferior a $1.200 \mathrm{~m}$ de altitude na Serra do Mar, enquanto na Serra da Mantiqueira estaria entre 1.300 e $1.400 \mathrm{~m}$. O limite altitudinal superior estaria a cerca de $2.000 \mathrm{~m}$ em Campos do Jordão, a $2.100 \mathrm{~m}$ na Serra do Mar, e a cerca de $2.300 \mathrm{~m}$ na Serra do Itatiaia, onde alcançam, às vezes, 100 a 200 m a mais em locais mais protegidos. Neste limite, a cobertura vegetal formaria uma mata de seis a oito metros de altura (Hueck 1972).

Para o sul do Estado de Minas Gerais, Azevedo (1962) descreveu variações fitofisionômicas decorrentes de condições diversas do clima, solos, altitude, relevo e duração da estação seca e reconheceu uma floresta distinta que cobriria as regiões elevadas da Mantiqueira, do planalto de Poços de Caldas e maciço do Itatiaia. Leitão Filho (1982) também destacou a ocorrência de uma fisionomia florestal exclusiva das áreas montanhosas da Serra da Mantiqueira associada a climas mais frios e composta por espécies com distribuição geográfica restrita. Porém, poucos foram os levantamentos realizados nas florestas montanas e alto-montanas no sudeste brasileiro e para a região da Serra da Mantiqueira pode-se citar Silva (1989), Fontes (1997), Guedes-Bruni (1998), Carvalho et al. (2000), Ribeiro (2003), França \& Stehmann (2004), Carvalho et al. (2005) e Pereira et al. (2006).

O presente estudo foi realizado na face oeste de uma área de altitude elevada da Serra da Mantiqueira, localizada no distrito de Monte Verde, Município de Camanducaia, Minas Gerais. O objetivo foi caracterizar a composição florística e a estrutura fitossociológica da formação florestal alto-montana em Monte Verde e verificar se a variação da altitude influenciaria na composição florística e nos parâmetros fitossociológicos ao longo de um curto gradiente altitudinal. Haveria nesta pequena escala mudanças na vegetação florestal capazes de serem detectadas em um levantamento fitossociológico? Estas mudanças na estrutura da vegetação seriam acompanhadas por uma substituição das espécies arbóreas ao longo deste gradiente? Estas mudanças estariam associadas ao acréscimo da altitude?

\section{Material e métodos}

O distrito de Monte Verde, Município de Camanducaia, Minas Gerais, apresenta um histórico de ocupação relativamente recente. Possui cotas altitudinais variando entre 1.550 e 2.082 m e está inserido na Serra da Mantiqueira, divisa com o Estado de São Paulo, nas coordenadas geográficas $22^{\circ} 51^{\prime} \mathrm{S}$ e $46^{\circ} 02^{\prime} \mathrm{W}$. O clima, no sistema de Koeppen, é Cwb, subtropical de altitude (Martins 2000). Machado Filho et al. (1983) descreveram a ocorrência de Cambissolos Álicos, nas áreas mais elevadas, e Latossolos Vermelho-Amarelo Distróficos nas áreas mais baixas. A Pedra do Selado, a $2.082 \mathrm{~m}$ de altitude, juntamente com o Platô, a 1.900 m, o Chapéu do Bispo, a 2.030 m, a Pedra Redonda, a 1.990 m e a Pedra Partida, a 2.050 m, correspondem aos picos da Serra da Mantiqueira nesta região, formados por rochas granitóides. Ocorre o predomínio de floresta ombrófila densa alto-montana (sensu Veloso 1992), além 
de floresta ombrófila mista alto-montana, afloramentos rochosos e campos de altitude com áreas alagadiças. Os campos de altitude representam, atualmente, a formação mais impactada e descaracterizada pela ocupação humana.

A amostragem foi realizada na região de captação de água do distrito, durante o primeiro semestre de 2002, entre as coordenadas $22^{\circ} 53^{\prime} 20^{\prime \prime} \mathrm{S}, 4^{\circ} 02^{\prime} 20^{\prime \prime} \mathrm{W}$ e $22^{\circ} 53^{\prime} 21^{\prime \prime} \mathrm{S}$, $46^{\circ} 02$ ' $21^{\prime \prime} \mathrm{W}$, a $1940 \mathrm{~m}$ de altitude, e $22^{\circ} 53^{\prime} 11^{\prime \prime} \mathrm{S}$, $46^{\circ} 02^{\prime} 21^{\prime \prime} \mathrm{W}$ e $22^{\circ} 53^{\prime} 11^{\prime \prime} \mathrm{S}, 46^{\circ} 02^{\prime} 19^{\prime \prime} \mathrm{W}$, a $1.820 \mathrm{~m}$ de altitude. Para descrever a vegetação e suas variações utilizou-se o método de parcelas. Foram instalados sete blocos paralelos com cinco parcelas contíguas de $10 \times 10 \mathrm{~m}$ alinhadas (figura 1). Os blocos distaram 50 metros entre suas estacas limítrofes superiores e ficaram em altitudes intermediárias de 1.820 a $1.940 \mathrm{~m}$ de altitude, com cerca de $300 \mathrm{~m}$ entre o primeiro e o sétimo bloco, perfazendo-se uma área amostral de $3.500 \mathrm{~m}^{2}$. O primeiro bloco (parcelas 1-5) foi instalado no topo do morro e o sétimo bloco (parcelas 31-35) ficou instalado dentro de um vale, próximo a um curso d'água. Amostraram-se todos os indivíduos arbóreos com circunferência a altura de 1,30 m do solo igual ou maior que $15 \mathrm{~cm}(\mathrm{CAP} \geq 15 \mathrm{~cm})$. Estes indivíduos tiveram sua altura e circunferência anotados, e receberam plaquetas numeradas em ordem crescente. Foram também amostradas as "moitas" de bambu, quando estas continham no mínimo dez perfilhos, anotando-se a circunferência de cada perfilho e estimando-se à altura total da moita. Considerou-se como indivíduo bifurcado os que apresentavam dois ou mais ramos a altura do peito para efetuarmos comparações entre cotas altitudinais. Exsicatas das espécies foram depositadas no herbário da Universidade Estadual de Campinas (UEC).

Para a descrição da estrutura florestal foram calculados os parâmetros fitossociológicos de densidade relativa, frequiência relativa, dominância relativa e o valor de importância, além do valor de cobertura (Muller-Dombois \& Ellenberg 1974). Utilizou-se o índice de diversidade de Shannon-Wiener, equabilidade de Pielou e o índice de Simpson (Magurran 1988), para a análise da heterogeneidade florística. Para o cálculo dos parâmetros fitossociológicos utilizou-se o programa Fitopac (Shepherd 1995).

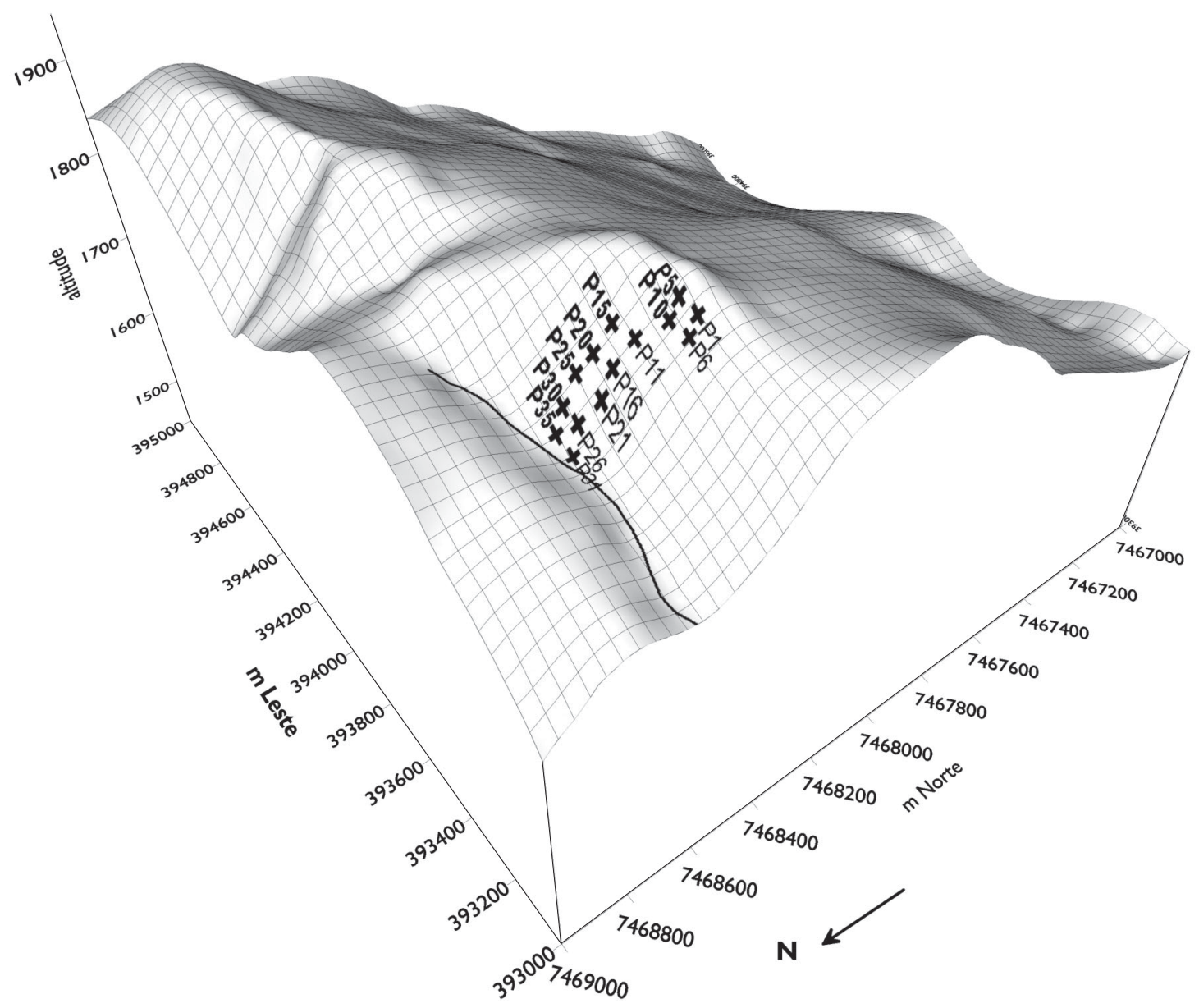

Figura 1. Localização geográfica do levantamento fitossociológico realizado no distrito de Monte Verde, Camanducaia, MG.

Figure 1. Geographical location of phytosociological inventory carried out in Monte Verde District, Camanducaia, MG. 
Para verificar a similaridade florística entre as parcelas foram realizadas análises de agrupamento e ordenação. Foi realizada uma análise "Twinspan" (Two Way Indicator Species Analysis - Hill et al. 1975), que é um método de agrupamento divisivo, que classifica simultaneamente as amostras e a ocorrência das espécies nos grupos formados (Valentin 2000). Para esta análise utilizou-se a presença e ausência das espécies nas parcelas. Para as análises de ordenação utilizou-se a abundância das espécies como descritores e as parcelas como unidades amostrais. Foram eliminadas as espécies representadas por um indivíduo ou presente somente em uma parcela e excluídas duas parcelas por possuírem elevada abundância de uma espécie. Os valores de abundância foram transformados para uma escala logarítmica normal. Realizou-se uma Análise de Correspondência (CA), que permite verificar a ocorrência de gradientes ambientais na ordenação das amostras (Kent \& Coker 1992) e uma Análise de Correspondência Distendida (DCA), que remove a relação quadrática entre o primeiro e o segundo eixo (efeito de arco), possível em uma CA (Kent \& Coker 1992). Para os cálculos utilizou-se o programa Fitopac (Shepherd 1995). A relação entre os escores das parcelas na DCA e o aumento da altitude foi calculada pelo método de regressão linear, no Programa Bioestat 2.0 (Ayres et al. 2000), para verificar se a ordenação das parcelas estava associada ao gradiente altitudinal.

Análises de regressão linear foram realizadas no Programa Bioestat 2.0 (Ayres et al. 2000) para analisar se as variações em alguns parâmetros fitossociológicos podem estar relacionadas com o gradiente altitudinal, utilizando as parcelas como unidades amostrais. Os parâmetros estruturais analisados foram altura máxima do dossel, número de espécies, número de indivíduos, diâmetro máximo, área basal, volume e número de indivíduos bifurcados. A relação entre a abundância de indivíduos mortos e de moitas de bambu nas parcelas também foi verificada por análise de regressão. Testes de rarefação foram realizados com o programa Ecosim (Gotelli \& Entsminger 2004) para cada bloco de parcelas para verificar se o número de espécies amostrado esteve relacionado ao o número de indivíduos para cada altitude amostrada. Os testes foram realizados para 20, 40, 60, 80, 100 e 120 indivíduos, calculando a riqueza de espécies esperada e o intervalo de confiança para cada sub-amostra escolhida.

\section{Resultados}

Foram amostrados 1.191 indivíduos, distribuídos entre 64 espécies arbóreas e duas espécies de bambus, pertencentes a 42 gêneros e 26 famílias, além da classe de indivíduos mortos (tabela 1). A família Myrtaceae (tabela 2) destacou-se por possuir o maior número de espécies (15), o maior número de indivíduos (336) e o maior VI $(65,33)$, seguida por Melastomataceae $(22,56)$,
Proteaceae $(21,12)$ e Winteraceae $(20,33)$. As famílias com maior número de espécies após Myrtaceae foram Asteraceae (seis espécies), Lauraceae e Aquifoliaceae (cinco espécies), Melastomataceae, Solanaceae e Cunoniaceae (três espécies). Sete famílias foram representadas por duas espécies, enquanto 12 famílias foram representadas por uma espécie. Os gêneros que apresentaram a maior riqueza foram Ilex, Myrceugenia e Myrcia (cinco espécies), Ocotea e Vernonanthura (três espécies). Os demais gêneros estiveram representados por duas ou uma espécie.

A densidade total estimada foi de 3.403 ind ha-1, enquanto a área basal estimada foi de $37,68 \mathrm{~m}^{2} \mathrm{ha}^{-1}$. O diâmetro e a altura média dos indivíduos foram iguais a $10,22 \mathrm{~cm}$ e $6,33 \mathrm{~m}$, respectivamente. O Índice de Diversidade de Shannon-Wiener $\left(H^{\prime}\right)$ foi de 3,284 nat ind ${ }^{-1}$, enquanto a equabilidade $(J)$ foi igual a 0,781 e o Índice de Simpson $(D)$ foi equivalente a 0,059. A necromassa (tabela 1) apresentou o maior valor de importância $(42,06)$ devido a elevada abundância (175 ind), a maior frequiência relativa $(7,19 \%)$ e a área basal $\left(20,18 \mathrm{~m}^{2} \mathrm{ha}^{-1}\right)$. Pimenta pseudocaryophyllus apresentou o maior VI $(24,59)$ após as mortas, acompanhada por Roupala rhombifolia $(19,98)$ e Drimys brasiliensis $(18,57)$, representando juntas cerca de $20 \%$ do VI total. Pimenta pseudocaryophyllus apresentou o maior número de indivíduos vivos (117) e a maior densidade relativa $(9,82 \%)$, mas sua dominância relativa $(9,97 \%)$ foi menor que a de Roupala rhombifolia (10,71\%), que apresentou indivíduos com maior área basal.

Miconia cinerascens destacou-se como a espécie de sub-bosque com o maior VI $(14,68)$, apresentando a segunda maior frequiência relativa $(6,10 \%)$, mas baixa dominância relativa (2,12\%). Myrceugenia myrcioides, outra espécie de sub-bosque, apresentou o maior número de indivíduos (91), após Pimenta pseudocaryophyllus. Entretanto, sua frequiência relativa foi baixa $(1,96 \%)$, pois ocorreu somente em 09 parcelas, entre 1.820 e $1.840 \mathrm{~m}$ de altitude. Em conjunto com Myrceugenia brevipedicellata, as espécies supracitadas apresentaram VI intermediários entre 14,6 e 13,1, representando 4,4 a $8,2 \%$ do VI total. Aureliana fasciculata, Lamanonia ternata, Leandra carassana, Macropeplus dentatus, Myrcia arborescens, Nectandra nitidula e Symplocos falcata também foram espécies que apresentaram VI > 7,0 e estiveram representadas por 17 a 49 indivíduos nesta amostragem.

Oito espécies contribuíram com $57 \%$ dos indivíduos vivos. Quatorze espécies foram representadas somente por um indivíduo na amostragem, correspondendo a $21 \%$ das espécies amostradas e 0,7\% dos indivíduos vivos. 
Tabela 1. Parâmetros fitossociológicos das espécies arbóreas $(\mathrm{CAP} \geq 15 \mathrm{~cm})$ amostradas na floresta alto-montana, distrito de Monte Verde, Camanducaia, MG (AB = abreviação para espécies; $\mathrm{NC}=$ número do coletor; $\mathrm{LDM}=$ Leonardo Dias Meireles; $\mathrm{NCF}=$ não coletada fértil; $\mathrm{N}=$ número de indivíduos amostrados; $\mathrm{FA}=$ frequência absoluta; $\mathrm{DR}=$ densidade relativa; $\mathrm{DRE}=$ dominância relativa; $\mathrm{VC}=$ valor de cobertura; $\mathrm{FR}$ = frequência relativa; $\mathrm{VI}=$ valor de importância).

Table 1. Phytosociological parameters for the trees species $(\mathrm{GBH} \geq 15 \mathrm{~cm})$ sampled on upper montane forest, Monte Verde District, Camanducaia, MG (AB = abbreviation for species; $\mathrm{NC}=$ number of collector; $\mathrm{LDM}=$ Leonardo Dias Meireles; $\mathrm{NCF}=$ no reproductive; $\mathrm{N}=$ Number of individuals; $\mathrm{FA}=$ absolute frequency; $\mathrm{DR}=$ relative density $\mathrm{DRE}=$ relative dominance; $\mathrm{VC}=$ cover value; $\mathrm{FR}=$ relative frequency; $\mathrm{VI}=$ importance value).

\begin{tabular}{|c|c|c|c|c|c|c|c|c|c|}
\hline Espécies & $\mathrm{AB}$ & $\begin{array}{c}\mathrm{NC} \\
\mathrm{LDM}\end{array}$ & $\mathrm{N}$ & FA & DR & DRE & $\mathrm{VC}$ & FR & VI \\
\hline Mortas & - & - & 175 & 94,2 & 14,69 & 20,18 & 34,87 & 7,19 & 42,06 \\
\hline \multicolumn{10}{|l|}{ Pimenta pseudocaryophyllus (Gomes) } \\
\hline Landrum & ppse & 357 & 117 & 62,8 & 9,82 & 9,97 & 19,80 & 4,79 & 24,59 \\
\hline Roupala rhombifolia Mart. ex Meisn. & rrho & 456 & 74 & 40,0 & 6,21 & 10,71 & 16,93 & 3,05 & 19,98 \\
\hline Drimys brasiliensis Miers & dbra & 467 & 81 & 68,5 & 6,80 & 6,54 & 13,34 & 5,23 & 18,57 \\
\hline Miconia cinerascens Miq. & mcin & 359 & 77 & 80,0 & 6,47 & 2,12 & 8,58 & 6,10 & 14,68 \\
\hline Myrceugenia myrcioides (Camb.) O. Berg & mmyr & 377 & 91 & 25,7 & 7,64 & 3,83 & 11,47 & 1,96 & 13,43 \\
\hline \multicolumn{10}{|l|}{ Myrceugenia brevipedicellata (Burret) } \\
\hline D. Legrand \& Kausel & mbre & 463 & 50 & 65,7 & 4,20 & 3,97 & 8,16 & 5,01 & 13,17 \\
\hline Nectandra nitidula Ness & nnit & 502 & 43 & 40,0 & 3,61 & 2,95 & 6,56 & 3,05 & 9,61 \\
\hline Leandra carassana (DC.) Cogn. & lean & 029 & 49 & 54,2 & 4,11 & 1,19 & 5,30 & 4,14 & 9,44 \\
\hline \multicolumn{10}{|l|}{ Macropeplus dentatus (Perkins) I. Santos } \\
\hline \& Peixoto & mden & 955 & 39 & 48,5 & 3,27 & 1,47 & 4,75 & 3,70 & 8,45 \\
\hline Symplocos falcata Brand & sfal & 604 & 29 & 54,2 & 2,43 & 1,82 & 4,25 & 4,14 & 8,39 \\
\hline Aureliana fasciculata (Vell.) Sendtn. & afas & 355 & 37 & 34,2 & 3,11 & 2,43 & 5,54 & 2,61 & 8,15 \\
\hline Lamanonia ternata Vell. & lter & 375 & 21 & 37,1 & 1,76 & 3,23 & 4,99 & 2,83 & 7,82 \\
\hline Myrcia arborescens O. Berg & marb & 630 & 17 & 28,5 & 1,43 & 3,72 & 5,15 & 2,18 & 7,33 \\
\hline Citronella paniculata (Mart.) R. A. Howard & cpan & 505 & 11 & 20,0 & 0,92 & 4,41 & 5,33 & 1,53 & 6,86 \\
\hline Croton celtidifolius Baill. & ccel & 490 & 23 & 42,8 & 1,93 & 0,88 & 2,81 & 3,27 & 6,08 \\
\hline Prunus myrtifolia (L.) Urb. & pmyr & 1050 & 18 & 37,1 & 1,51 & 0,75 & 2,26 & 2,83 & 5,09 \\
\hline Symplocos celastrinea Mart. ex Miq. & scel & 958 & 17 & 34,2 & 1,43 & 0,64 & 2,06 & 2,61 & 4,68 \\
\hline Chusquea aff. meyeriana Rupr. ex Döll & cmey & 1020 & 15 & 22,8 & 1,26 & 1,17 & 2,43 & 1,74 & 4,17 \\
\hline Myrceugenia scutellata D. Legrand & $m s c u$ & 609 & 9 & 14,2 & 0,76 & 2,24 & 2,99 & 1,09 & 4,08 \\
\hline Solanum sp. & sola & 755 & 9 & 22,8 & 0,76 & 0,87 & 1,62 & 1,74 & 3,37 \\
\hline Myrsine umbellata Mart. & mumb & 342 & 14 & 17,1 & 1,18 & 0,85 & 2,03 & 1,31 & 3,34 \\
\hline Piptocarpha axillaris (Less.) Baker & paxi & 366 & 8 & 22,8 & 0,67 & 0,79 & 1,47 & 1,74 & 3,21 \\
\hline Ilex theezans Mart. ex Reissek & ithe & 634 & 9 & 17,1 & 0,76 & 1,07 & 1,82 & 1,31 & 3,13 \\
\hline Baccharis oreophila Malme & bore & 353 & 8 & 17,1 & 0,67 & 1,10 & 1,77 & 1,31 & 3,08 \\
\hline Rhamnus sphaerosperma $\mathrm{Sw}$. & $r s p h$ & 790 & 11 & 20,0 & 0,92 & 0,46 & 1,39 & 1,53 & 2,91 \\
\hline Ilex taubertiana Reissek & itau & 788 & 8 & 22,8 & 0,67 & 0,33 & 1,00 & 1,74 & 2,74 \\
\hline Cabralea canjerana (Vell.) Mart. & ccan & 379 & 8 & 22,8 & 0,67 & 0,91 & 1,58 & 1,74 & 2,67 \\
\hline Vernonanthura puberula (Less.) H. Rob. & $v p u b$ & 347 & 8 & 14,2 & 0,67 & 0,25 & 0,92 & 1,09 & 2,67 \\
\hline Myrcia montana Cambess & mmon & 575 & 9 & 20,0 & 0,76 & 0,28 & 1,04 & 1,53 & 2,56 \\
\hline Myrcia laruotteana Cambess. & mlar & 678 & 7 & 20,0 & 0,59 & 0,31 & 0,90 & 1,53 & 2,42 \\
\hline Myrceugenia ovalifolia (O. Berg) Landrum & movl & 386 & 9 & 14,2 & 0,76 & 0,43 & 1,18 & 1,09 & 2,27 \\
\hline
\end{tabular}


continuação

\begin{tabular}{|c|c|c|c|c|c|c|c|c|c|}
\hline Especies & $\mathrm{AB}$ & $\begin{array}{l}\mathrm{NC} \\
\mathrm{LDM}\end{array}$ & $\mathrm{N}$ & FA & DR & DRE & $\mathrm{VC}$ & FR & VI \\
\hline Solanum evonymoides Sendtn. & sevo & 668 & 4 & 8,5 & 0,34 & 0,96 & 1,30 & 0,65 & 1,95 \\
\hline Ilex microdonta Reissek & imic & $\mathrm{NCF}$ & 4 & 11,4 & 0,34 & 0,71 & 1,04 & 0,87 & 1,91 \\
\hline Myrsine gardneriana A. DC. & mgar & 487 & 7 & 14,2 & 0,59 & 0,21 & 0,80 & 1,09 & 1,89 \\
\hline Eugenia involucrata DC. & - & 764 & 12 & 2,8 & 1,01 & 0,60 & 1,61 & 0,22 & 1,83 \\
\hline Chusquea leptophylla Nees & clep & 1181 & 6 & 8,5 & 0,50 & 0,63 & 1,13 & 0,65 & 1,79 \\
\hline Eugenia sp. & euge & $\mathrm{NCF}$ & 5 & 14,2 & 0,42 & 0,09 & 0,51 & 1,09 & 1,60 \\
\hline Siphoneugena dussii (Krug \& Urb.) Proença & - & 599 & 1 & 2,8 & 0,08 & 1,22 & 1,30 & 0,22 & 1,52 \\
\hline Myrceugenia ovata (Hook. \& Arn.) O. Berg & mova & 435 & 5 & 5,7 & 0,42 & 0,39 & 0,81 & 0,44 & 1,25 \\
\hline Weinmannia organensis Gardner & worg & 1042 & 3 & 5,7 & 0,25 & 0,43 & 0,68 & 0,44 & 1,11 \\
\hline Psychotria vellosiana Benth. & pvel & 339 & 4 & 8,5 & 0,35 & 0,08 & 0,42 & 0,65 & 1,07 \\
\hline Weinmannia paulliniifolia Pohl & wpau & 760 & 2 & 5,7 & 0,17 & 0,44 & 0,61 & 0,44 & 1,05 \\
\hline Escallonia bifida Link \& Otto & ebif & 011 & 2 & 5,7 & 0,17 & 0,26 & 0,43 & 0,44 & 0,87 \\
\hline Meliosma sellowii Urb. & - & 1061 & 3 & 2,8 & 0,25 & 0,34 & 0,59 & 0,22 & 0,81 \\
\hline Ilex paraguariensis A. St.-Hil. & ipar & 484 & 2 & 5,7 & 0,17 & 0,17 & 0,34 & 0,44 & 0,77 \\
\hline Rollinia emarginata Schltdl. & rema & 1033 & 3 & 5,7 & 0,25 & 0,08 & 0,33 & 0,44 & 0,77 \\
\hline Myrcia guianensis (Aubl.) DC. & mgui & 504 & 2 & 5,7 & 0,17 & 0,09 & 0,26 & 0,44 & 0,70 \\
\hline Gordonia fruticosa (Schrad.) H. Keng & gfru & 524 & 2 & 5,7 & 0,17 & 0,09 & 0,26 & 0,44 & 0,70 \\
\hline Tibouchina fothergillae (DC.) Cogn. & tfot & 960 & 2 & 5,7 & 0,17 & 0,05 & 0,22 & 0,44 & 0,66 \\
\hline Clethra scabra Pers. & - & 321 & 1 & 2,8 & 0,08 & 0,32 & 0,40 & 0,22 & 0,62 \\
\hline Persea pyrifolia Spreng. & - & NCF & 1 & 2,8 & 0,08 & 0,20 & 0,28 & 0,22 & 0,50 \\
\hline Vernonanthura diffusa (Less.) H. Rob. & - & 1554 & 1 & 2,8 & 0,08 & 0,18 & 0,26 & 0,22 & 0,48 \\
\hline Ilex amara (Vell.) Loes. & - & 812 & 2 & 2,8 & 0,17 & 0,07 & 0,24 & 0,22 & 0,46 \\
\hline Ocotea nutans $\mathrm{Mez}$ & - & 591 & 1 & 2,8 & 0,08 & 0,14 & 0,22 & 0,22 & 0,44 \\
\hline Vernonanthura discolor (Spreng.) H. Rob. & - & 1554 & 2 & 2,8 & 0,17 & 0,05 & 0,22 & 0,22 & 0,43 \\
\hline Piptocarpha regnelii (Sch. Bip.) Cabrera & - & $\mathrm{NCF}$ & 2 & 2,8 & 0,17 & 0,04 & 0,21 & 0,22 & 0,43 \\
\hline Guatteria australis A. St.-Hill. & - & 723 & 2 & 2,8 & 0,17 & 0,04 & 0,21 & 0,22 & 0,43 \\
\hline Senna tropica (Vell.) H. S. Irwin \& Barneby & - & 789 & 1 & 2,8 & 0,08 & 0,04 & 0,13 & 0,22 & 0,35 \\
\hline Mollinedia clavigera Tull. & - & 401 & 1 & 2,8 & 0,08 & 0,04 & 0,12 & 0,22 & 0,34 \\
\hline $\begin{array}{l}\text { Calyptranthes grandifolia (O. Berg.) D. } \\
\text { Legrand }\end{array}$ & - & 745 & 1 & 2,8 & 0,08 & 0,03 & 0,12 & 0,22 & 0,33 \\
\hline Ocotea puberula Nees & - & 356 & 1 & 2,8 & 0,08 & 0,03 & 0,11 & 0,22 & 0,33 \\
\hline Myrcia fallax (Rich.) DC. & - & 717 & 1 & 2,8 & 0,08 & 0,03 & 0,11 & 0,22 & 0,33 \\
\hline Euplassa itatiaiae Sleumer & - & 716 & 1 & 2,8 & 0,08 & 0,02 & 0,11 & 0,22 & 0,33 \\
\hline Ocotea vaccinioides $\mathrm{Mez}$ & - & $\mathrm{NCF}$ & 1 & 2,8 & 0,08 & 0,02 & 0,11 & 0,22 & 0,33 \\
\hline Xylosma ciliatifolia (Clos) Eichler & - & 374 & 1 & 2,8 & 0,08 & 0,02 & 0,10 & 0,22 & 0,32 \\
\hline Casearia decandra Jacq. & - & 1553 & 1 & 2,8 & 0,08 & 0,01 & 0,10 & 0,22 & 0,32 \\
\hline
\end{tabular}

Estas espécies obtiveram freqüência relativa equivalente a $0,22 \%$. Outras cinco espécies também obtiveram frequiência relativa equivalente a $0,22 \%$, mas estavam representadas por dois a 13 indivíduos nas parcelas onde ocorriam.
A análise "Twinspan" diferenciou as parcelas nas menores altitudes $(1.820 \mathrm{~m}-1.840 \mathrm{~m})$ das demais, no primeiro nível de separação com um auto-valor de 0,443 . Nestas parcelas, Myrceugenia myrcioides e Myrceugenia scutellata representaram espécies exclusivas, além de 
Tabela 2. Relação dos parâmetros fitossociológicos das famílias coletadas na floresta alto-montana, distrito de Monte Verde, Serra da Mantiqueira, $\mathrm{MG}(\mathrm{N}$ = número de indivíduos amostrados; $\mathrm{NE}=$ número de espécies; $\mathrm{FA}$ = frequência absoluta; $\mathrm{DR}=$ densidade relativa; $\mathrm{DRE}=$ dominância relativa; $\mathrm{VC}=$ valor de cobertura; $\mathrm{FR}$ = frequência relativa; $\mathrm{VI}=$ valor de importância).

Table 2. Phytosociological parameters for the botanical families sampled on upper montane forest, Monte Verde district, Camanducaia, $\mathrm{MG}(\mathrm{N}$ = number of individuals; $\mathrm{NE}=$ number of species; $\mathrm{FA}=$ absolute frequency; $\mathrm{DR}$ = relative density; $\mathrm{DRE}=$ relative dominance; $\mathrm{VC}=$ cover value; $\mathrm{FR}=$ relative frequency; $\mathrm{VI}=$ importance value) .

\begin{tabular}{|c|c|c|c|c|c|c|c|c|}
\hline Família & $\mathrm{N}$ & NS & FA & DR & DRE & $\mathrm{VC}$ & FR & VI \\
\hline Myrtaceae & 336 & 15 & 97,14 & 28,21 & 27,21 & 55,42 & 9,91 & 65,33 \\
\hline Mortas & 175 & 1 & 94,29 & 14,69 & 20,18 & 34,87 & 9,62 & 44,49 \\
\hline Melastomataceae & 128 & 3 & 82,86 & 10,75 & 3,36 & 14,10 & 8,45 & 22,56 \\
\hline Winteraceae & 81 & 1 & 68,57 & 6,80 & 6,54 & 13,34 & 7,00 & 20,34 \\
\hline Proteaceae & 75 & 2 & 40,00 & 6,30 & 10,74 & 17,03 & 4,08 & 21,12 \\
\hline Solanaceae & 50 & 3 & 57,14 & 4,20 & 4,26 & 8,46 & 5,83 & 14,29 \\
\hline Symplocaceae & 46 & 2 & 65,71 & 3,86 & 2,45 & 6,32 & 6,71 & 13,02 \\
\hline Lauraceae & 47 & 5 & 48,57 & 3,95 & 3,34 & 7,29 & 4,96 & 12,25 \\
\hline Cunoniaceae & 26 & 3 & 42,86 & 2,18 & 4,10 & 6,28 & 4,37 & 10,65 \\
\hline Asteraceae & 29 & 6 & 48,57 & 2,43 & 3,07 & 5,50 & 4,96 & 10,46 \\
\hline Monimiaceae & 40 & 2 & 51,43 & 3,36 & 1,51 & 4,87 & 5,25 & 10,12 \\
\hline Aquifoliaceae & 25 & 5 & 45,71 & 2,10 & 2,34 & 4,44 & 4,66 & 9,11 \\
\hline Cardiopteridaceae & 11 & 1 & 20,00 & 0,92 & 4,41 & 5,33 & 2,04 & 7,37 \\
\hline Euphorbiaceae & 23 & 1 & 42,86 & 1,93 & 0,88 & 2,81 & 4,37 & 7,18 \\
\hline Poaceae & 21 & 2 & 25,71 & 1,76 & 1,80 & 3,56 & 2,62 & 6,19 \\
\hline Rosaceae & 18 & 1 & 37,14 & 1,51 & 0,75 & 2,26 & 3,79 & 6,05 \\
\hline Myrsinaceae & 21 & 2 & 25,71 & 1,76 & 1,07 & 2,83 & 2,62 & 5,45 \\
\hline Rhamnaceae & 11 & 1 & 20,00 & 0,92 & 0,46 & 1,39 & 2,04 & 3,43 \\
\hline Meliaceae & 8 & 1 & 22,86 & 0,67 & 0,25 & 0,92 & 2,33 & 3,26 \\
\hline Annonaceae & 5 & 2 & 8,57 & 0,42 & 0,12 & 0,54 & 0,87 & 1,42 \\
\hline Rubiaceae & 4 & 1 & 8,57 & 0,34 & 0,08 & 0,42 & 0,87 & 1,29 \\
\hline Escalloniaceae & 2 & 1 & 5,71 & 0,17 & 0,26 & 0,43 & 0,58 & 1,02 \\
\hline Sabiaceae & 3 & 1 & 2,86 & 0,25 & 0,34 & 0,59 & 0,29 & 0,88 \\
\hline Theaceae & 2 & 1 & 5,71 & 0,17 & 0,09 & 0,26 & 0,58 & 0,84 \\
\hline Flacourtiaceae & 2 & 2 & 5,71 & 0,17 & 0,03 & 0,20 & 0,58 & 0,79 \\
\hline Clethraceae & 1 & 1 & 2,86 & 0,08 & 0,32 & 0,40 & 0,29 & 0,69 \\
\hline Leguminosae & 1 & 1 & 2,86 & 0,08 & 0,04 & 0,13 & 0,29 & 0,42 \\
\hline
\end{tabular}

Aureliana fasciculata, Citronela paniculata e Myrsine gardneriana que ocorreram preferencialmente próximas ao curso d'água. Na segunda separação, as parcelas nas cotas altitudinais superiores $(1.920 \mathrm{~m}-1.940 \mathrm{~m})$ foram discriminadas das parcelas em cotas altitudinais intermediárias (1.860 m-1.900 m). Chusquea leptophylla, Chusquea aff. meyriana, Eugenia involucrata, Myrsine umbellata e Roupala rhombifolia, estiverem restritas às parcelas nas maiores cotas altitudinais, enquanto Drimys brasiliensis e Pimenta pseudocaryophyllus representaram espécies não preferencias, ocorrendo simultanenamente nestas parcelas. Entre $1.860 \mathrm{~m}$ e $1.900 \mathrm{~m}$, somente Psychotria vellosiana ocorreu como exclusiva, enquanto Leandra carassana, Nectandra nitidula e Piptocarpha axillaris representaram espécies preferenciais desta faixa altitudinal.

Na CA observou-se um acentuado efeito do arco, demonstrando haver uma forte substituição de espécies ao longo do gradiente amostrado (figura 2). A ordenação das parcelas refletiu a distribuição espacial dos blocos 


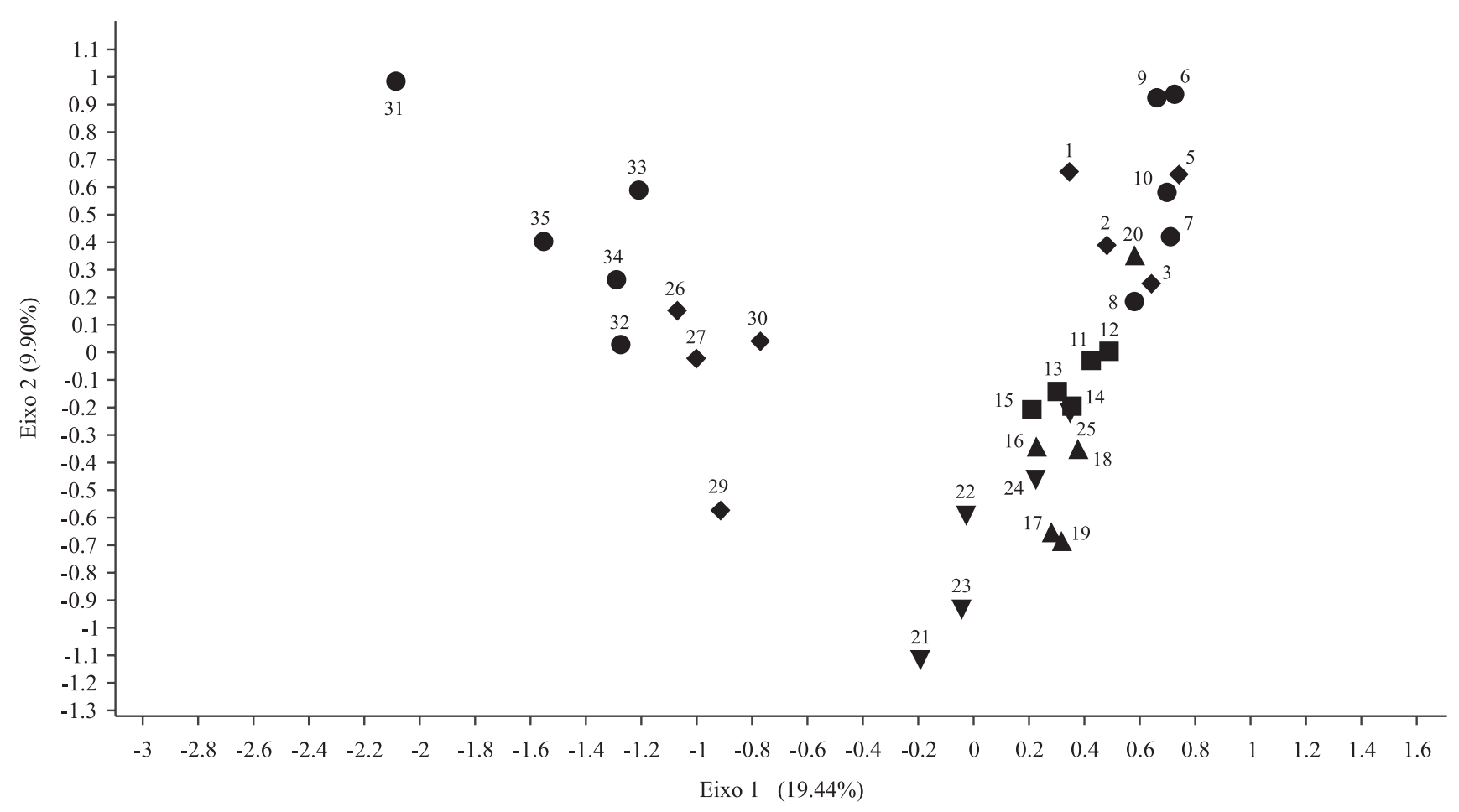

Figura 2. Diagrama de ordenação de uma Análise de Componentes (CA) calculados a partir da abundância das espécies na floresta alto-montana, distrito de Monte Verde, Camanducaia, MG (Esquerda: Bloco 7 ( $\bullet$ ) e Bloco 6 ( ), Direita: Bloco $5(\boldsymbol{\nabla})$, Bloco $4(\boldsymbol{\Delta})$, Bloco $3(\boldsymbol{\bullet})$, Bloco $2(\bullet)$ e Bloco $1(\bullet))$.

Figure 2. Components Analysis ordination diagram (CA) calculated from the species' abundance in plots on upper montane forest, Monte Verde district, Camanducaia, MG (Left: Block 7 (•) and Block 6 ( ), Right: Block 5 ( $\boldsymbol{\vee}$ ), Block 4 ( $\bullet$ ), Block $3(\square)$, Block $2(\bullet)$ and Block $1(\bullet))$.

amostrais, indicando haver diferentes condições ecológicas ao longo do gradiente altitudinal amostrado. As parcelas próximas ao curso d'água e nas menores altitudes estiveram restritas a um extremo do gradiente identificado pela CA, enquanto as parcelas nas cotas altitudinais intermediárias distribuiram-se ao longo deste e as localizadas nas maiores cotas ficaram restritas ao outro extremo. Os autovalores para os dois primeiros eixos foram 0,5349 e 0,2724 e os únicos com inércia calculada maior que a inércia aleatoriamente esperada, com porcentagem cumulativa de inércia de $29,3 \%$. Na DCA observou-se a ordenação das parcelas ao longo do eixo 1 conforme sua posição no gradiente altitudinal, como também uma dispersão das parcelas na mesma cota altitudinal ao longo do eixo 2 (figura 3). Os autovalores para estes eixos foram 0,5353 e 0,1437, respectivamente. Os escores das parcelas amostrais ao longo do eixo 1 apresentaram uma relação linear negativa com o aumento da altitude $(Y=4393,94-2.2728$ Alt, $\left.R^{2}=0,8325, P=0,00\right)$.
A altura máxima do dossel apresentou uma relação linear negativa com o aumento da altitude $(Y=78.693$ 0,036 Alt, $\left.R^{2}=0,550, P=0,00\right)$ e foi menor na maior cota altitudinal em relação às demais altitudes (tabela 3 ). Na menor cota altitudinal $(1.820 \mathrm{~m})$ os indivíduos possuíam até $14,0 \mathrm{~m}$ de altura, observando-se dois estratos arbóreos, enquanto na cota mais elevada $(1.940 \mathrm{~m})$ os indivíduos não ultrapassaram $9,0 \mathrm{~m}$, com somente um estrato arbóreo. Para o número de indivíduos bifurcados a altura do peito observou-se uma relação linear positiva $\left(Y=-122.914+0,68 \mathrm{Alt}, R^{2}=0,421, P=0,00\right)$. A maior densidade de indivíduos bifurcados a altura do peito foi registrada a $1.940 \mathrm{~m}$, correspondendo a $38,7 \%$ dos indivíduos amostrados nestas parcelas, enquanto que para os demais blocos, essa proporção variou entre 3,5\% a $14,9 \%$ dos indivíduos amostrados (tabela 3 ).

A variação no número de indivíduos não apresentou relação linear com o aumento da altitude $\left(R^{2}=0,00\right.$, $P=0,917)$, mas foi menor nos extremos do gradiente altitudinal em relação às parcelas em altitudes 


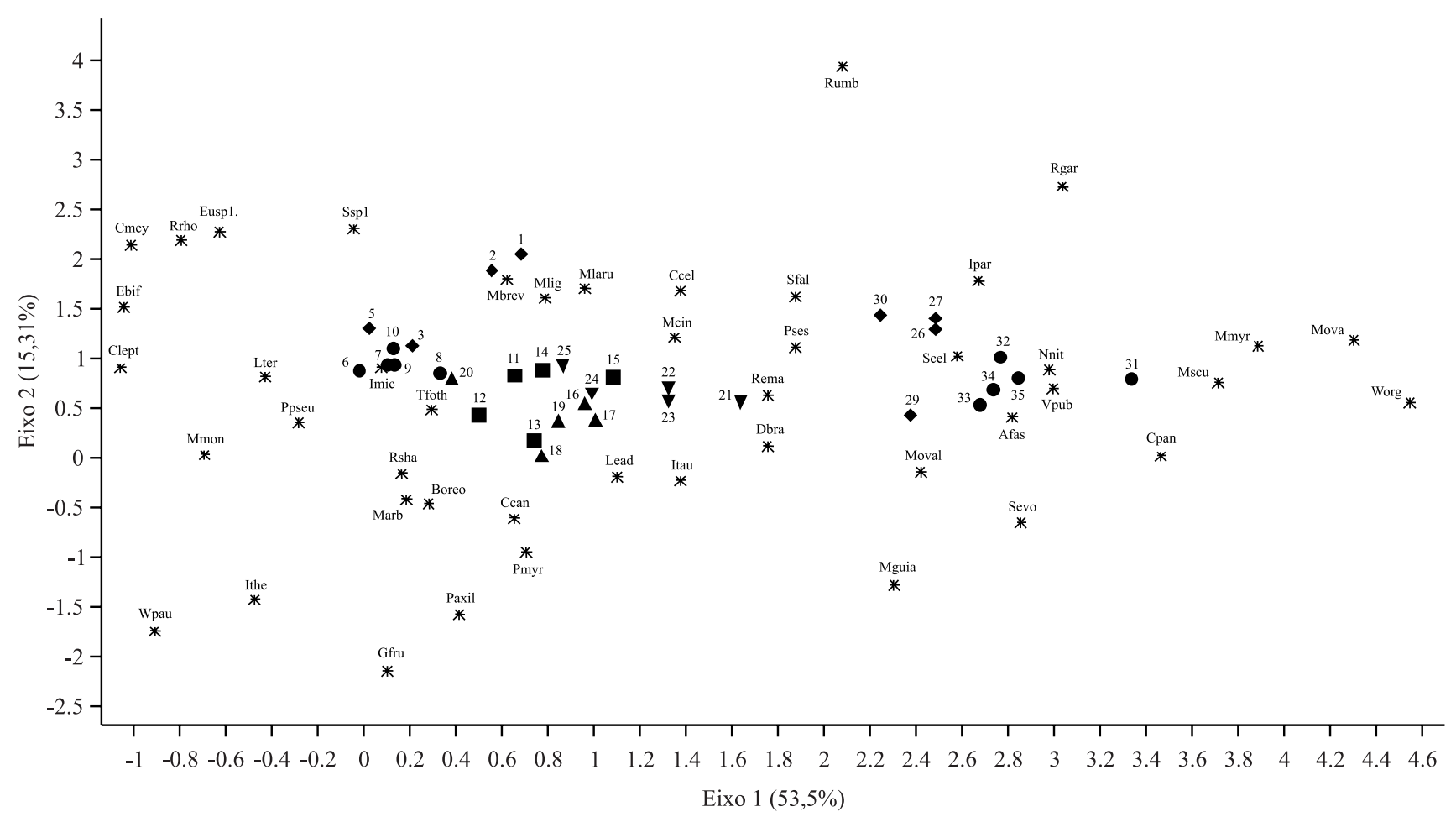

Figura 3. Diagrama de ordenação de uma Análise de Correspondência Distendida (DCA) calculados a partir da abundância das espécies (espécies (*), abreviaturas na tabela 1) na floresta alto-montana no distrito de Monte Verde, Serra da Mantiqueira, MG, segundo tabela 1 (Esquerda: Bloco $1(\bullet)$, Bloco $2(\bullet)$, Bloco $3(\boldsymbol{\bullet})$, Bloco $4(\boldsymbol{\Delta})$ e Bloco $5(\boldsymbol{\nabla})$, Direita: Bloco 7 $(\bullet)$ e Bloco $6(\bullet))$.

Figure 3. Ordination diagram of a DCA calculated from the species' abundance on upper montane forest (species (*) according to table 1), Monte Verde District, Camanducaia, MG, see table 1 (Left: Block 1 ( ), Block 2 (•), Block 3 ( $\bullet$ ), Block 4 ( $\bullet$ ) and Block 5 ( $\mathbf{v})$, Right: Block 7 (•) and Block $6(\bullet))$.

Tabela 3. Paramêtros fitossociológicos, índice de diversidade e altitude dos blocos amostrais instalados no levantamento fitossociológico realizado na floresta alto-montana no distrito de Monte Verde, Camanducaia, MG (PARC = parcelas; $\mathrm{N}=$ número de indivíduos; $\mathrm{AM}=$ altura máxima $(\mathrm{m}) ; \mathrm{AME}=$ altura média $(\mathrm{m}) ; \mathrm{DM}=$ diâmetro máximo $(\mathrm{cm}) ; \mathrm{DME}=$ diâmetro médio $(\mathrm{cm}) ; \mathrm{AB}=$ área basal total $\left(\mathrm{m}^{2}\right) ; \mathrm{VOL}=$ volume $\left(\mathrm{m}^{3}\right) ; \mathrm{IS}=$ índice de Shannon-Wiener; $\mathrm{NP}=$ número de indivíduos perfilhados; $\mathrm{PP}=$ porcentagem de indivíduos perfilhados; N.SP = número de espécies; $\mathrm{N} . \mathrm{FM}=$ número de famílias; $\mathrm{ALT}=$ altitude do bloco).

Table 3. Phytosociological parameters, diversity index and altitude for blocks sampled on upper montane forest, Monte Verde district, Camanducaia, $\mathrm{MG}(\mathrm{PARC}=$ plots; $\mathrm{N}=$ number of individuals; $\mathrm{AM}=$ maximum height $(\mathrm{m}) ; \mathrm{AME}=$ median height $(\mathrm{m}) ; \mathrm{DM}=$ maximum diameter $(\mathrm{cm}) ; \mathrm{DME}=$ median diameter $(\mathrm{cm}) ; \mathrm{AB}=$ basal area $\left(\mathrm{m}^{2}\right) ; \mathrm{VOL}=$ Volume $\left(\mathrm{m}^{3}\right) ; \mathrm{IS}=$ Shannon-Wiener's index; NP = number of branched individuals; PP = percentage of branched individuals; N.SP = number of species; N.FM = number of families; ALT = altitude of blocks).

\begin{tabular}{ccccccccccccccc}
\hline Bloco & PARC & N & AM & AME & DM & DME & AB & VOL & IS & NP & PP & N.SP & N.FM & ALT \\
\hline 1 & $1-5$ & 142 & 9,0 & 5,34 & 36,93 & 11,27 & 1,8021 & 10,72 & 2,548 & 55 & 38,7 & 26 & 17 & 1940 \\
2 & $6-10$ & 161 & 12,0 & 6,23 & 42,01 & 10,96 & 2,0529 & 15,58 & 2,691 & 24 & 14,9 & 31 & 18 & 1920 \\
3 & $11-15$ & 200 & 12,0 & 6,15 & 52,20 & 9,76 & 2,0929 & 16,14 & 2,797 & 7 & 3,5 & 32 & 18 & 1900 \\
4 & $16-20$ & 194 & 11,0 & 6,41 & 32,19 & 10,13 & 2,0290 & 15,23 & 2,748 & 20 & 10,3 & 33 & 19 & 1880 \\
5 & $21-25$ & 185 & 12,0 & 6,40 & 31,19 & 9,79 & 1,7917 & 13,68 & 2,900 & 9 & 4,9 & 33 & 20 & 1860 \\
6 & $26-30$ & 174 & 14,0 & 7,05 & 42,65 & 9,45 & 1,6350 & 15,35 & 2,448 & 9 & 5,2 & 22 & 15 & 1840 \\
7 & $31-35$ & 135 & 14,0 & 6,61 & 45,20 & 10,65 & 1,7845 & 16,73 & 2,435 & 17 & 12,6 & 22 & 15 & 1820 \\
\hline
\end{tabular}


intermediárias (tabela 3). Para o número de espécies por parcela $\left(R^{2}=0,017, P=0,461\right)$ a relação linear em relação a altitude não foi significativa. Entretanto, as áreas com as maiores riqueza de espécies (31 a 33 spp.) estiveram entre os blocos 2 e 5 (tabela 3 ), locais com o maior número de indivíduos amostrados (161-200 ind). Os testes de rarefação estimaram que os blocos nos extremos do gradiente altitudinal apresentavam menor número de espécies quando comparados com os blocos de 2 a 5, entre $1.860 \mathrm{~m}$ e $1.920 \mathrm{~m}$, com diferenças significativas a partir de 120 indivíduos. Os locais com menor riqueza estimada foram os blocos 6 e 7 (1.840 m$1.820 \mathrm{~m})$, acompanhados do bloco 1 (1.940 m). Os demais blocos apresentaram riqueza estimada similares, não apresentando diferenças significativas para os valores de sub-amostras escolhidos (figura 4). Os demais parâmetros testados, como diâmetro máximo $\left(R^{2}=0,0071\right.$, $P=0,123)$, área basal $\left(R^{2}=0,033, P=0,30\right)$ e volume $\left(R^{2}=0,064, P=0,141\right)$, não apresentaram regressões lineares significativas. Também não se verificou uma correlação significativa entre a abundância de indivíduos mortos e a presença das moitas de bambu nas parcelas amostrais $\left(R^{2}=0,333, P=0,175\right)$.

\section{Discussão}

Mudanças na riqueza e importância relativa das famílias podem ser observadas em florestas montanas por todo o globo, em resposta a longos gradientes altitudinais (Kitayama 1992, Oliveira-Filho \& Fontes 2000). Hueck (1972) citou a importância florística das famílias Myrtaceae, Proteaceae, Melastomataceae, Malpighiaceae, Cunoniaceae e Asteraceae para as florestas do topo da Serra da Mantiqueira. Na floresta alto-montana em Monte Verde, estas famílias apresentaram altos valores de importância, bem como Lauraceae, Monimiaceae, Solanaceae, Symplocaceae e Winteraceae. Somente Malpighiaceae não esteve representada neste levantamento.

Myrtaceae, que geralmente representa a família mais rica em diferentes formações florestais atlânticas (Mori et al. 1983), destacou-se pelo elevado valor de

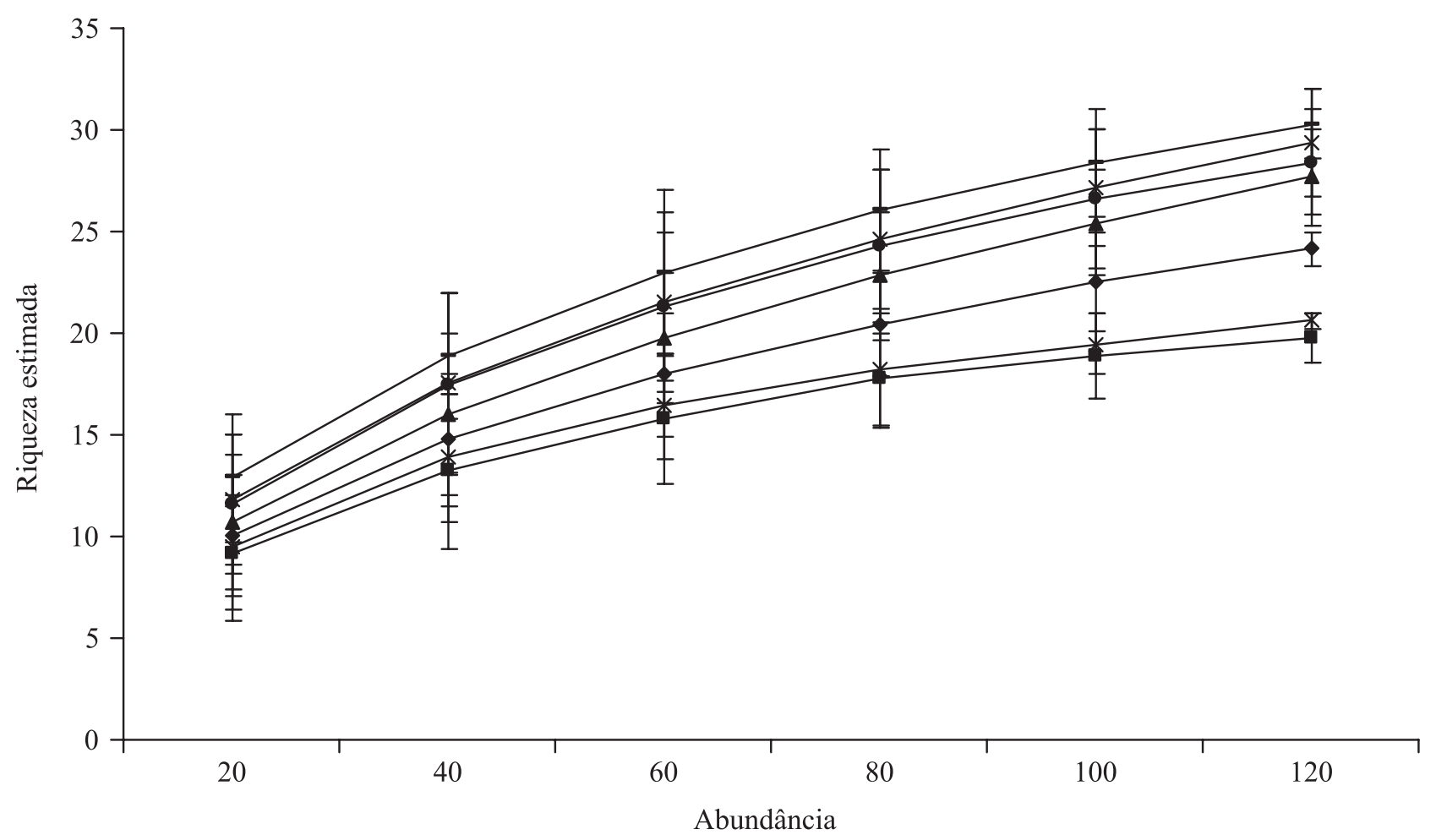

Figura 4. Estimativas de riqueza para os blocos amostrais na floresta alto-montana, distrito de Monte Verde, Camanducaia, MG (Blocos amostrais de cima para baixo: Bloco 5 ( - ), Bloco 4 ( x ), Bloco 3 ( • ), Bloco 2 ( $\Delta$ ), Bloco 1 ( $\bullet$ ), Bloco 7 $(*)$ e Bloco $6(\boldsymbol{\square}))$.

Figure 4. Richness estimates for sample blocks established in upper montane forest, Monte Verde District, Camanducaia, MG (Blocks from top to bottom: Block 5 ( - ), Block 4 ( x ), Block $3(\bullet)$, Block 2 ( $\Delta$ ), Block 1 ( $\bullet$ ), Block 7 ( * ) and Block $6(\boldsymbol{\square}))$. 
importância, número de indivíduos e de espécies. Meyer (1963) descreveu o predomínio dessa família nas formações florestais sobre influência da neblina na Argentina, sendo esta também a família mais rica nas matas nebulares sulinas (Falkenberg \& Voltolini 1995). Esses levantamentos demonstram a importância das espécies desta família na constituição florística de florestas alto-montanas e nebulares austrais da América do Sul.

Oliveira-Filho \& Fontes (2000) descreveram o aumento da importância relativa das famílias Asteraceae, Melastomataceae e Solanaceae e o decréscimo da importância relativa de Leguminosae, para a Floresta Atlântica no Sudeste brasileiro, relacionado ao aumento da altitude. Leguminosae figurou como a família com o menor valor de importância, enquanto as anteriores estiveram entre as famílias com os maiores valores de importância em Monte Verde. França \& Stehmann (2004) encontraram para uma floresta alto-montana próxima a Monte Verde uma composição florística similar, e também identificaram variações na representativadade das famílias para as florestas alto-montanas ao sul da Serra da Mantiqueira Meridional, associadas ao aumento da altitude.

Outras famílias com importância relativa elevada nas florestas em cotas altitudinais inferiores do sudeste, como Meliaceae, Annonaceae, Flacourtiaceae e Rubiaceae apresentaram baixa importância relativa neste levantamento, enquanto Moraceae e Rutaceae estiveram ausentes (Leitão Filho 1982). Além disso, Escalloniaceae foi registrada pela primeira vez em levantamentos florestais realizados no sudeste brasileiro. Esta apresenta táxons exclusivos de áreas elevadas e frias da América do Sul (Safford 1999), estando ausente nas florestas de altitudes médias e baixas do sudeste brasileiro.

Dentre os gêneros, Ilex, Myrceugenia, Roupala e Weinmannia são citados como importantes na composição florística de florestas alto-montanas. Ilex apresenta elevada riqueza nas florestas montanas e alto-montanas do Paraná (Roderjan 1994, Portes \& Galvão 2002), em florestas ripárias nos campos rupestres da Cadeia do Espinhaço e florestas semidecíduas de altitude e restingas no sudeste (Peron 1989, Oliveira-Filho \& Fontes 2000). Myrceugenia, o gênero mais freqüente e abundante nesta amostragem, distribui-se preferencialmente ao longo da costa leste nos planaltos brasileiros, em elevações superiores a 900-1000 m, sob clima frio e úmido (Landrum 1981). No maciço do Itatiaia este gênero também apresentou elevada riqueza em diferentes formações vegetacionais altimontanas (Lima et al. 2004), destacando sua importância na composição florística em áreas de altitude da Serra da Mantiqueira. Nesta amostragem, Myrceugenia brevipedicellata, que destacou-se como a espécie com o sexto maior VI, representa uma espécie endêmica das áreas acima de $1.500 \mathrm{~m}$ para a região sul da Mantiqueira Meridional (Landrum 1981). O gênero Roupala apresenta várias espécies típicas de áreas de altitude e foi citado como dominante nas formações alto-montanas da Serra do Itatiaia (Segadas-Viana 1965, Lupo \& Pirani 2002). Por outro lado, Weinmannia, um gênero freqüente em várias florestas sob influência da neblina no globo (Merlin \& Juvik 1995), esteve representado por duas espécies, mas com poucos indivíduos.

Drimys brasiliensis, Pimenta pseudocaryophyllus e Roupala rhombifolia, espécies ocorrentes preferencialmente em áreas elevadas do sudeste brasileiro (Landrum 1986, Ehrendorfer et al. 1979, Lupo \& Pirani 2002), apresentaram os maiores valores de importância neste levantamento. Apesar de D. brasiliensis ser observada em outras formações florestais em cotas altitudinais inferiores, como na floresta atlântica de encosta e em matas de galeria (Ehrendorfer et al. 1979), este apresenta geralmente hábito arbustivo. Neste levantamento vários indivíduos desta espécie eram de grande porte e com biomassa elevada, sugerindo que esta espécie apresenta seu melhor desenvolvimento em ambientes altimontanos.

O número elevado de indivíduos mortos, com altos valores de área basal, refletiu-se no maior valor de importância observado. Pôde-se observar durante os anos de visita à área que, durante o início do ano, ocorre uma elevada queda de indivíduos arbóreos de maior porte, acentuada pela alta pluviosidade e incidência de raios, favorecida pela declividade do relevo local. Em Monte Verde, os bambus constituem parte do dossel, apresentando grande importância fisionômica. Onde as moitas de bambu continham poucos perfilhos, o subbosque apresentava-se mais conservado, enquanto nas áreas onde as moitas alcançavam maior diâmetro e altura, o sub-bosque e indivíduos arbóreos estavam ausentes, podendo-se observar alguns troncos mortos.

Não se observou uma forte correlação entre a ocorrência de árvores mortas e a presença de moitas de bambu nas parcelas. Isto pode significar que no estágio maduro da floresta não seja possível determinar de forma clara que a presença de bambus em matas causa alta mortalidade de árvores. Young (1991) verificou que uma espécie de Chusquea, nas florestas montanas do Peru, não afetava a mortalidade, composição, ou regeneração de espécies arbóreas. Mas a alta mortalidade de indivíduos arbóreos e o ciclo de vida dos bambus são fatores 
importantes para a dinâmica florestal em ambientes altimontanos por deterem grande parte da biomassa total e permitirem a abertura natural de clareiras, processos que necessitam ser estudados. Moradores locais relataram que as espécies de bambus do gênero Chusquea ocorrentes em Monte Verde apresentam um ciclo de florescimento de cerca de sete anos, podendo ocorrer uma florada em massa que termina com a morte de grande parte da população dessas espécies.

O índice de diversidade de Shannon-Wiener (3,284 nat ind ${ }^{-1}$ ) apresentou valor semelhante, mas geralmente inferior, aos de levantamentos realizados em florestas montanas do sudeste acima de $1.000 \mathrm{~m}$ de altitude (Rodrigues et al. $1989=3,94$ nat ind $^{-1}$, Guedes-Bruni et al. $1997=4,05$ nat ind $^{-1}$, Werneck et al. $2000=3,15$ nat ind ${ }^{-1}$, Meguro et al. $1996=4,14$ nat ind $^{-1}$ ) e superior aos de levantamentos realizados em florestas altomontanas do sul do país (Roderjan $1994=2,22$ nat ind $^{-1}$, Rocha $1999=2,91$ nat ind $^{-1}$, Falkenberg $2003=0,93$ nat ind ${ }^{-1}$ e 1,54 nat ind ${ }^{-1}$ ). Estes trabalhos estão sujeitos a diferentes históricos de perturbação, associados a diferentes floras e riquezas regionais, além de utilizarem métodos de amostragem e critérios de inclusão diferentes, dificultando comparações diretas entre os valores de diversidade calculados (Martins \& Santos 1999). Mas os valores relativamente baixos para as florestas altomontanas sulinas sugerem que elas são menos ricas em espécies e apresentam abundância concentrada em poucas espécies.

O aumento da dominância relativa por espécie nas zonas mais elevadas, que implicaria numa redução no número de espécies, associada à redução na capacidade de dispersão destas, têm sido relacionados à substituição florística verificada em formações florestais ao longo de gradientes altitudinais (Ohsawa 1984, Kitayama 1992). As análises multivariadas demonstraram um forte gradiente de substituição florística ao longo do gradiente altitudinal nesta região da Serra da Mantiqueira. Esta surpreendente substituição florística foi evidenciada pela variação da abundância e dominância relativa das espécies, mesmo sendo o desnível altitudinal curto, cerca de $120 \mathrm{~m}$. Houve uma maior similaridade entre parcelas próximas, localizadas na mesma cota altitudinal. $\mathrm{O}$ gradiente de substituição florística pôde ser identificado nas análises multivariadas através do "efeito do arco" observado na CA. Este efeito na ordenação das amostras indica a ocorrência de gradientes, isto é, que a distribuição e a abundância das espécies variam gradualmente ao longo da área de amostragem e que as variáveis que influenciariam esta comunidade mudariam continuamente (Digby \& Kempton 1987).
A análise "Twinspan" demonstrou haver um conjunto distinto de espécies restritas às diferentes cotas altitudinais amostradas. Roupala rhombifolia, por exemplo, ocorreu somente acima de $1.880 \mathrm{~m}$ de altitude, perfazendo $32 \%$ dos indivíduos amostrados a $1.940 \mathrm{~m}$ de altitude, enquanto Myrceugenia myrcioides ocorreu até $1.840 \mathrm{~m}$ de altitude, perfazendo 33\% dos indivíduos amostrados a $1.820 \mathrm{~m}$ de altitude. A DCA ordenou as parcelas ao longo do eixo 1 conforme sua posição ao longo do gradiente altitudinal, com um elevado autovalor associado. A altitude esteve fortemente associada aos escores das parcelas ao longo deste eixo. Isto evidencia que a altitude é uma importante variável explanatória para a presença e abundância das espécies ao longo desta escarpa da Serra da Mantiqueira, não excluindo outras variáveis a ela correlacionadas, como variáveis climáticas, e a variação interna nas condições ambientais também observadas.

Com o aumento da altitude, esperava-se que o número de indivíduos por hectare aumentasse, que houvesse decréscimo da altura dos indivíduos do dossel, do diâmetro médio, da área basal por hectare e do número de espécies por área (Weaver et al. 1986). Os indivíduos arbóreos amostrados, na sua maioria, apresentavam troncos pouco desenvolvidos e vários eram perfilhados a altura do peito e densamente cobertos por briófitas, como esperado para florestas alto-montanas. A floresta amostrada apresentou elevada densidade e área basal estimada de 3.403 ind ha ${ }^{-1}$ e $37,68 \mathrm{~m}^{2} \mathrm{ha}^{-1}$, respectivamente. Em outro fragmento florestal em condições fisiográficas distintas, na mesma região desta amostragem, França \& Stehmann (2004) encontram uma densidade estimada de 2.001 ind ha $^{-1} \mathrm{e}$ uma área basal estimada de $48,12 \mathrm{~m}^{2} \mathrm{ha}^{-1}$. Carvalho et al. (2005) encontraram para outro fragmento florestal, na região norte da Mantiqueira Meridional, uma densidade estimada de 2.475 ind ha ${ }^{-1}$ e uma área basal estimada de $33,27 \mathrm{~m}^{2} \mathrm{ha}^{-1}$, valores indicados como um dos mais elevados comparados a outros levantamentos de floresta montana daquela região.

As condições fisiográficas entre as amostragens citadas variam consideravelmente, com altitudes entre 1.200 e 1.900 m e diferentes condições de exposição em relação à cadeia central da Serra da Mantiqueira. Diferenças relacionadas ao histórico de pertubação, efeito de borda, condições edáficas, presença de água também devem ser observadas para tornar estas comparações mais confiáveis (Carvalho et al. 2005). Entretanto, a elevada densidade observada na floresta de Monte Verde destaca-se das demais florestas tanto desta região, como de florestas em cotas altitudinais inferiores, demonstrando que a elevação da altitude 
causada pela Serra da Mantiqueira pode permitir uma diferenciação estrutural entres matas em diferentes cotas altitudinais, como esperado para o efeito da altitude na estrutura de comunidades florestais (Whitmore 1998).

A altura máxima dos indivíduos apresentou uma relação linear significativa com o aumento da altitude. Beard (1955) citou que formações florestais montanas apresentam um dossel contínuo sem árvores emergentes e que o dossel gradualmente diminui até se unir com o sub-bosque. A floresta em Monte Verde apresentou dois estratos arbóreos nos blocos em menor altitude e um estrato arbóreo no bloco de maior altitude, com o dossel tornando-se mais plano e regular. Essas mudanças nestes parâmetros estruturais podem estar associadas à maior exposição ao vento, pois as parcelas com dossel mais alto se localizam em áreas menos expostas, dentro de um vale, enquanto os blocos com dossel mais baixo estão localizados no topo do morro, onde há maior circulação de massas de ar e ocorre a formação de neblina.

Para florestas montanas australianas, Herwitz \& Young (1994) sugeriram que parte da baixa estatura das florestas nos topos das montanhas poderia ser explicada pelo crescimento lento e taxa elevada de mortalidade de árvores grandes (DAP $>30 \mathrm{~cm}$ ), comparados com as taxas de crescimento e mortalidade nas áreas de baixada. Alguns dos indivíduos mortos na floresta alto-montana em Monte Verde eram de grande porte, sugerindo existir um limite máximo de altura e circunferência para os indivíduos se manterem vivos nestes ambientes onde a ação dos ventos, a declividade do terreno e a profundidade do solo poderiam limitar seu porte e, conseqüentemente, a altura do dossel. Entretanto, Bellingham \& Tanner (2000) não encontraram os mesmos resultados nas florestas tropicais montanas da Jamaica e afirmaram não ser possível fazer simples generalizações sobre a dinâmica de florestas no topo e florestas na baixada em montanhas tropicais, havendo outras explicações para a estatura baixa dos indivíduos nestas áreas de altitude (Lawton 1982).

Os extremos do gradiente altitudinal apresentaram menor riqueza e densidade e maior número de indivíduos perfilhados do que nas altitudes intermediárias, sugerindo a ocorrência de fatores ambientais limitantes nos extremos do gradiente amostrado. Os testes de rarefação demonstraram que nos extremos do gradiente o número de espécies esperado é menor do que para as áreas nas altitudes intermediárias. O maior número e proporção de indivíduos bifurcados foi observado no bloco na maior altitude sugerindo que a exposição à ação dos ventos pode estar influenciando a arquitetura das espécies que ocupam essa área (Lawton 1982). As parcelas na maior altitude, a $1.940 \mathrm{~m}$, correspondem ao local mais exposto à ação dos ventos e da neblina, enquanto as parcelas nas menores cotas altitudinais, entre $1.820 \mathrm{~m}$ e $1.840 \mathrm{~m}$, estão mais protegidas da ação dos ventos, mas estão sob influência de um curso d'água. Estas condições abióticas podem estar associadas às diferenças observadas entre os extremos e as áreas intermediárias deste gradiente, destacando que distintos fatores limitantes podem causar modificações estruturais similares nos extremos do gradiente altitudinal amostrado.

Os demais parâmetros fitossociológicos analisados não demonstraram regressões lineares significativas com a altitude. Diâmetro ou circunferência, área basal e volume são dependentes da frequência dos indivíduos de maior porte, que ocorreram ocasionalmente ao longo do gradiente altitudinal. Lieberman et al. (1996) afirmaram que amostragens em florestas tropicais ao longo de um curto gradiente altitudinal não descrevem com precisão as mudanças nos parâmetros fitossociológicos em relação à altitude, e a falta de réplicas limitaria a interpretação das similaridades entre as faixas altitudinais amostradas, impedindo testes de hipóteses confiáveis (Santos et al. 1998).

Estudos realizados em florestas estacionais semidecíduas, por exemplo, demonstraram diferentes correlações entre variáveis topográficas e edáficas para explicar a organização florística e estrutural (Botrel $e t$ al. 2002, Espírito-Santo et al. 2002), sugerindo que as variáveis associadas à organização espacial das espécies, entre comunidades vegetais, mudam de caso a caso. Lieberman et al. (1985) citaram que pouco se conhece sobre quais fatores influenciam na composição de espécies ao longo de uma pequena escala, conhecendose menos ainda sobre a distribuição das espécies em resposta a estes fatores.

A altitude é uma variável ambiental indireta de grande importância para a caracterização dos tipos vegetacionais da Floresta Atlântica (Scudeller et al. 2001), mas distintos fatores locais podem influenciar na vegetação dentro de uma mesma cota altitudinal, não nos permitindo indicar sem medições e análises pertinentes quais os demais fatores envolvidos nesta brusca substituição florística e nas mudanças estruturais observadas nesta amostragem. De fato, as parcelas mais expostas à ação dos ventos, no extremo do gradiente altitudinal, ou próximas ao curso d'água apresentaram estrutura e florística distintas em comparação às parcelas não submetidas a estes fatores.

Este levantamento permitiu-nos verificar que esta floresta alto-montana da Serra da Mantiqueira apresenta uma composição florística bastante distinta das florestas em cotas altitudinais inferiores, apresentando vários 
táxons restritos às regiões elevadas, distinguindo-se também na fisionomia devido a altura do dossel, densidade e diâmetro dos indivíduos. Pôde-se verificar variações na sua estrutura fitossociológica desta floresta, devido às mudanças nas condições abióticas locais e uma acentuada substituição florística, mesmo num curto gradiente altitudinal.

Agradecimentos - Os autores agradecem à Capes pela bolsa de mestrado concedida ao primeiro autor e à Fundação de Amparo à Pesquisa do Estado de São Paulo (Fapesp) pelo auxílio ao projeto (01/07245). À Pós-Graduação em Biologia Vegetal e ao Departamento de Botânica pelo apoio oferecido. Ao Dr. Geraldo Damasceno, Dr. Roque Cielo Filho e Ms. Roberta Macedo pelo auxílio em algumas análises realizadas. Aos diversos taxonomistas consultados, principalmente Dra. Ariane Luna Peixoto, Dr. João B. Baitelo, Dr. João Renato Stehman, Biólogo Marcos Sobral, Dr. Renato Goldenberg e Dr. Milton Groppo Júnior. Ao Instituto Estadual de Florestas de Minas Gerais, à Companhia Melhoramentos Florestal, ao senhor Egon Boettcher e ao senhor Verner Grinberg (in memorian) pelas autorizações e apoio concedidos para a realização deste trabalho.

\section{Referências bibliográficas}

AUSTIN, M.P., CUNNINGHAM, R.B. \& FLEMING, P.M. 1984. New approaches to direct gradient analysis using environmental scalars and statistical curve-fitting procedures. Vegetatio 55:11-27.

AYRES, M., AYRES JUNIOR., M., AYRES, D.L. \& SANTOS, A.S. 2000. BioEstat 2.0: aplicações nas áreas das ciências biológicas e médicas. Sociedade Civil Mamirauá, Belém.

AZEVEDO, L.G. 1962. Tipos de vegetação do sul de Minas e campos da Mantiqueira (Brasil). Anais da Academia Brasileira de Ciências 34:225-234.

BEARD, J.S. 1955. The classification of tropical American vegetation types. Ecology 36:89-100.

BELLINGHAM, P.J. \& TANNER, E.V.J. 2000. The influence of topography on tree growth, mortality, and recruitment in a tropical montane forest. Biotropica 32:378-384.

BOTREL, R.J., OLIVEIRA-FILHO, A.T., RODRIGUES, L.A. \& CURI, N. 2002. Influência do solo e topografia sobre as variações da composição florística e estrutura da comunidade arbóreo-arbustiva de uma floresta estacional semidecidual em Ingaí, MG. Revista Brasileira de Botânica 25:195-213.

CARVALHO, D.A., OLIVEIRA-FILHO, A.T., VAN DEN BERG, E., FONTES, M.A.L., VILELA, E.A., MARQUES, J.J.G.S.M. \& CARVALHO, W.A.C. 2005. Variações florísticas e estruturais do componente arbóreo de uma floresta ombrófila alto-montana às margens do Rio Grande, Bocaina de Minas, MG, Brasil. Acta Botanica Brasilica 19:91-109.
CARVALHO, L.M.T., FONTES, M.A.L. \& OLIVEIRA-FILHO, A.T. 2000. Tree species distribution in canopy gaps and mature forest in an area of cloud forest of the Ibitipoca Range, south-eastern Brazil. Plant Ecology 149:9-22.

DIGBY, P.G.N. \& KEMPTON, R.A. 1987. Multivariate analysis of ecological communities. Chapman \& Hall, Londres.

EHRENDORFER, F., SILBERBAUER-GOTTSBERGER, I. \& GOTTSBERGER, G. 1979. Variation on the population, racial, and species level in the primitive relic angiosperm genus Drimys (Winteraceae) in South America. Plant Systematics and Evolution 132:53-83.

ESPÍRITO-SANTO, F.D.B., OLIVEIRA-FILHO, A.T., MACHADO, E.L.M., SOUZA, J.S., FONTES, M.A.L. \& MARQUES, J.J.G.S.M. 2002. Variáveis ambientais e a distribuição de espécies arbóreas em um remanescente de floresta estacional semidecídua montana no campus da Universidade Federal de Lavras, MG. Acta Botanica Brasilica 16:331-356.

FALKENBERG, D.B. 2003. Matinhas nebulares e vegetação rupícola dos Aparados da Serra Geral (SC/RS), sul do Brasil. Tese de doutorado, Universidade Estadual de Campinas, Campinas.

FALKENGERG, D.B. \& VOLTOLINI, J.C. 1995. The montane cloud forest in Southern Brazil. In Tropical montane cloud forest (L.S. Hamilton, J.O. Juvik \& F.N. Scatena, eds.). Springer-Verlag, New York, p.138-149.

FONTES, M.A. 1997. Análise da composição florística das florestas nebulares do Parque Estadual do Ibitipoca, Minas Gerais. Tese de mestrado, Universidade Federal de Lavras, Lavras.

FRANÇA, G.S. \& STEHMANN, J.R. 2004. Composição florística e estrutura do componente arbóreo de uma floresta altimontana no município de Camanducaia, Minas Gerais, Brasil. Revista Brasileira de Botânica 27:19-30.

GOTELLI, N.J. \& ENTSMINGER, G.L. 2004. Ecosim: null models software for ecology. Version 7. Acquired Intelligence Inc. \& Kesey-Bear.

GUEDES-BRUNI, R.R. 1998. Composição, estrutura e similaridade florística de dossel em seis unidades fisionômicas de Mata Atlântica no Rio de Janeiro. Tese de doutorado, Universidade de São Paulo, São Paulo.

GUEDES-BRUNI, R.R., PESSOA, S.V.A. \& KURTZ, B.C. 1997. Florística e estrutura do componente arbustivoarbóreo de um trecho preservado de floresta montana na Reserva Ecológica de Macaé de Cima. In Serra de Macaé de Cima: diversidade florística e conservação da Mata Atlântica (H.C. Lima \& R.R. Guedes-Bruni, eds.). Editora do Jardim Botânico do Rio de Janeiro, Rio de Janeiro, p.127-146.

HAMILTON, L.S., JUVIK, J.O. \& SCATENA, F.N. 1995. The Puerto Rico tropical cloud forest symposium: introduction and workshop synthesis. In Tropical montane cloud forest (L.S. Hamilton, J.O. Juvik \& F.N. Scatena, eds.). Springer-Verlag, New York, p.1-23. 
HERWITZ, S. \& YOUNG, S.S. 1994. Mortality, recruitment, and growth rates of montane tropical rain forest canopy trees on Mont Bellender-Ker, northeast Queensland, Australia. Biotropica 26:350-361.

HILL, M.O., BUNCE, R.G.H. \& SHAW, M.W. 1975. Indicator species analysis, a divisive polythetic method of classification, and its application to a survey of native pinewoods in Scotland. Journal of Ecology 63:597-613.

HUECK, K. 1972. As florestas da América do Sul. Editora da Universidade de Brasília, Brasília.

KENT, M. \& COKER, P. 1992. Vegetation description and analysis. John Wiley \& Sons, New York.

KITAYAMA, K. 1992. An altitudinal transect study of the vegetation on Mount Kinabalu, Borneo. Vegetatio 102:149-171.

LANDRUM, L.R. 1981. A monograph of the genus Myrceugenia (Myrtaceae). Flora Neotropica, 29:1-137.

LANDRUM, L.R. 1986. Campomanesia, Pimenta, Blepharocalyx, Legrandia, Acca, Myrrhinium and Luma (Myrtaceae). Flora Neotropica 45:78-115.

LAWTON, R.O. 1982. Wind stress and elfin stature in a montane rain forest tree: an adaptive explanation. American Journal of Botany 69:1224-1230.

LEITÃO FILHO, H.F. 1982. Aspectos taxonômicos das florestas do Estado de São Paulo. Silvicultura em São Paulo 16:197-296.

LIEBERMAN, M., LIEBERMAN, D., HARTSHORN, G.S. \& PERALTA, R. 1985. Small-scale altitudinal variation in lowland wet tropical forest vegetation. Journal of Ecology 73:505-516.

LIEBERMAN, D., LIEBERMAN, M., PERALTA, R. \& HARTSHORN, G.S. 1996. Tropical forest structure and composition on a large-scale altitudinal gradient in Costa Rica. Journal of Ecology 84:137-152.

LIMA, W.G. \& GUEDES-BRUNI, R.R. 2004. Myrceugenia (Myrtaceae) ocorrentes no Parque Nacional do Itatiaia, Rio de Janeiro. Rodriguésia 55:73-94.

LUPO, R. \& PIRANI, J.R. 2002. Proteaceae In Flora fanerogâmica do Estado de São Paulo (M.G.L. Wanderley, G.J. Shepherd \& A.M. Giulietti, eds.). Fapesp, Hucitec, São Paulo, v.2, p.269-280.

MACHADO FILHO, L., RIBEIRO, M.W., GONZALEZ, S.R., SCHENINI, C.A., SANTOS-NETO, A., PALMEIRA, R.C.B., PIRES, J.L., TEIXEIRA, W. \& CASTRO, H. E.F. 1983. Geologia. In Projeto RADAMBRASIL. Folhas SF:23/24 Rio de Janeiro/Vitória; geologia, geomorfologia, pedologia, vegetação e uso potencial da terra. MEE/SG, Rio de Janeiro, v.32, p.56-66.

MAGURRAN, A.E. 1988. Ecological diversity and its measurement. Princeton University Press, Princeton.

MARTINS, C.S. 2000. Caracterização física e fitogeográfica de Minas Gerais. In Lista vermelha das espécies ameaçadas de extinção da flora de Minas Gerais. (M.P. Mendonça \& L.V. Lins, orgs.). Fundação Biodiversitas, Belo Horizonte, p.35-43.
MARTINS, F.R. \& SANTOS, F.A.M. 1999. Técnicas usuais de estimativa da Biodiversidade. Revista Holos 1:236-267.

MEGURO, M., PIRANI, J.R., MELLO-SILVA, R. \& GIULIETTI, A.M. 1996. Caracterização florística e estrutural de matas ripárias e capões de altitude da Serra do Cipó, Minas Gerais. Boletim de Botânica da Universidade de São Paulo 15:13-29.

MERLIN, M.D. \& JUVIK, J.O. 1995. Montane cloud forest in the Tropical Pacific some aspects of their floristics, biogeography, ecology and conservation. In Tropical montane cloud forest (L.S. Hamilton, J.O. Juvik \& F.N. Scatena, eds.). Springer-Verlag, New York, p.234-253.

MEYER, T. 1963. Estudios sobre la Selva Tucumana: La Selva de Mirtaceaes de "Las Pavas". Opera Lilloana 10:1-144.

MOREIRA, A.A.N. \& CAMALIER, C. 1977. Relevo. In Geografia do Brasil (Fundação Instituto Brasileiro de Geografia e Estatística ed.). IBGE, Rio de Janeiro, v.3, p.1-150.

MORI, S.A., BOOM, B.M., CARVALINO, A. de M. \& SANTOS, T. dos S. 1983. Ecological importance of Myrtaceae in an eastern brazilian wet forest. Biotropica 15:68-70.

MULLER-DOMBOIS, D. \& ELLENBERG, H. 1974. Aims and methods of vegetation ecology. John Wiley \& Sons, New York.

OGDEN, J. \& POWELL, J.A. 1979. A quantitative description of the forest vegetation on an altitudinal gradient in the Mount Field National Park, Tasmania, and a discussion of its history and dynamics. Australian Journal of Ecology 4:293-325.

OHSAWA, M. 1984. Differentiation of vegetation zones and species strategies in the subalpine region of Mt. Fuji. Vegetatio 57:15-52.

OLIVEIRA-FILHO, A.T. \& FONTES, M.A.L. 2000. Patterns of floristic differentiation among Atlantic Forest in southeastern Brazil and the influence of climate. Biotropica 32:793-810.

PENDRY, C.A. \& PROCTOR, J. 1997. Altitudinal zonation of rain forest on Bukit Belalong, Brunei: soils, forest structure and floristic. Journal of Tropical Ecology 13:221-241.

PEREIRA, I.M., OLIVEIRA-FILHO, A.T., BOTELHO, S.A., CARVALHO, W.A.C., FONTES, M.A.L., SCHIAVINI, I. \& SILVA, A.F. 2006. Composição florística do compartimento arbóreo de cinco remanescentes florestais do maciço do Itatiaia, Minas Gerais e Rio de Janeiro. Rodriguésia 57:103-126.

PERON, M.V. 1989. Listagem preliminar da flora fanerogâmica dos campos rupestres do Parque Estadual do Itacolomi - Ouro Preto/Mariana, MG. Rodriguésia 67:63-69.

PORTES, M.C.G. de O. \& GALVÃO, F. 2002. A floresta altomontana do sul do Brasil: considerações climáticas, pedológicas e vegetacionais. Cadernos da Biodiversidade 3:44-50. 
PROCTOR, J., LEE, Y.F., LANGLEY, A.M., MUNRO, W.R.C. \& NELSON, T. 1988. Ecological studies on Gunung Silam, a small ultrabasic mountain in Sabah, Malaysia. I. Environment, forest structure and floristics. Journal of Ecology 76:320-340.

RIBEIRO, C.A.N. 2003. Florística e fitossociologia de um trecho de Floresta Atlântica de altitude da Fazenda da Neblina, Parque Estadual da Serra do Brigadeiro, Minas Gerais. Tese de mestrado, Universidade Federal de Viçosa, Viçosa.

ROCHA, M.R.L. 1999. Caracterização fitossociológica e pedológica de uma floresta ombrófila densa altomontana no Parque Estadual Pico do Marumbi - Morretes. PR. Tese de mestrado, Universidade Federal do Paraná, Curitiba.

RODERJAN, C.V. 1994. A floresta ombrófila densa altomontana do Morro do Anhangava, Quatro Barras, $\mathrm{PR}$ - aspectos climáticos, pedológicos e fitossociológicos. Tese de doutorado, Universidade Federal do Paraná, Curitiba.

RODRIGUES, R.R., MORELLATO, L.P.C., JOLY, C.A. \& LEITÃO FILHO, H.F. 1989. Estudo florístico e fitossociológico em um gradiente altitudinal de mata estacional mesófila semidecídua, na Serra do Japi, Jundiaí, SP. Revista Brasileira de Botânica 12:71-84.

SAFFORD, H.D. 1999. Brazilian Páramos I. An introduction to the physical environment and vegetation of the campos de altitude. Journal of Biogeography 26:693712.

SALIS, S.M., SHEPHERD, G.J. \& JOLY, C.A. 1995. Floristic comparison of mesophytic semideciduous forest of the interior of the state of São Paulo, Southeast Brazil. Vegetatio 119:115-164.

SANTOS, F.A.M., PEDRONI, F., ALVES, L.F. \& SANCHEZ, M. 1998. Structures and dynamics of tree species of the Atlantic Forest. Anais da Academia Brasileira de Ciências 70:873-880.

SCUDELLER, V.V., MARTINS, F.R. \& SHEPHERD, G.J. 2001. Distribution and abundance of arboreal species in the atlantic ombrophilous dense forest in southeastern Brazil. Plant Ecology 80:705-717.

SEGADAS-VIANNA, F. 1965. Ecology of the Itatiaia Range, Southeastern Brazil. I. Altitudinal zonation of the vegetation. Arquivos do Museu Nacional 53:7-30.
SHEPHERD, G.J. 1995. FITOPAC 1. Manual do usuário. Departamento de Botânica. Unicamp.

SILVA, A.F. 1989. Composição florística e estrutura fitossociológica do estrato arbóreo da Reserva Florestal Professor Augusto Ruschi, São José dos Campos, SP. Tese de doutorado, Universidade Estadual de Campinas, Campinas.

SILVA, A.F. \& LEITÃO FILHO, H.F. 1982. Composição florística e estrutura de um trecho de Mata Atlântica de Encosta no município de Ubatuba, São Paulo, Brasil. Revista Brasileira de Botânica 5:43-52.

TANNER, E.V.J. 1977. Four montane rain forests of Jamaica: a quantitative characterization of the floristics, the soils and the foliar mineral levels, and a discussion of the interrelations. Journal of Ecology 65:883-918.

TORRES, R.B., MARTINS F.R. \& KINOSHITA, L.S. 1997. Climate, soil and tree flora relationships in forests in the state of São Paulo, southeastern Brazil. Revista Brasileira de Botânica 20:41-49.

VALENTIN, J.L. 2000. Ecologia numérica: uma introdução à análise multivariada de dados ecológicos. Editora Interciência. Rio de Janeiro.

VÁZQUEZ, J.A. \& GIVNISH, T.J. 1998. Altitudinal gradients in tropical forest composition, structure, and diversity in the Sierra de Manantlán. Journal of Ecology 86:999-1020.

VELOSO, H.P. 1992. Sistema fitogeográfico. In Manual técnico da vegetação brasileira. (Instituto Brasileiro de Geografia e Estatística ed.) IBGE, Rio de Janeiro, p.9-38.

WEAVER, P.L., MEDINA, E., POOL, D., DUGGER, K., GONZALES-LIBOY, J. \& CUEVAS, E. 1986. Ecological observations in the dwarf cloud forest of the Luquillo Mountains in Puerto Rico. Biotropica 18:79-85.

WERNECK, M.S., PEDRALli, G., KOENIG, R. \& GISEKE, L.F. 2000. Florística e estrutura de três trechos de uma floresta semidecídua na Estação Ecológica do Tripuí, Ouro Preto, MG. Revista Brasileira de Botânica 23:97-106.

WHITMORE, T.C. 1998. An introduction to tropical rain forests. $2^{\text {nd }}$ ed. Oxford University Press, Oxford.

YOUNG, K.R. 1991. Natural history of an understory bamboo (Chusquea sp.) in a tropical timberline forest. Biotropica 23:542-554. 